\title{
The Impact of R\&D Employees' Income on Work Engagement in High-tech Industries: Based on A Moderated Mediation Model
}

\author{
Xing Li \\ CAS Key Laboratory of Behavioral Science, Institute of \\ Psychology. and Department of PsychologyUniversity of \\ Chinese Academy of Sciences \\ lixing8603@163.com
}

\begin{abstract}
Based on the social exchange theory and job demand-resource model, this paper discusses the relationship between the R\&D employees' income and work engagement in high-tech industry, and explores the internal mechanism of job satisfaction, organizational commitment and sense of income equity. The results show that income has a significant positive effect on work engagement. It is also identified that job satisfaction and organizational commitment have a completely mediating effect between income and work engagement, and that the sense of income equity moderates the mediating role of job satisfaction and organizational commitment. This paper proposes a new approach to illustrate the impact of income on work engagement, which enriches the theoretical model framework of income and provides theoretical guidance for enterprises to improve employees' work engagement.
\end{abstract}

\section{CCS CONCEPTS}

- Social and professional topics $\rightarrow$ Professional topics; Professional topics; Management of computing and information systems; Project and people management;

\section{KEYWORDS}

income, work engagement, job satisfaction, organizational commitment, sense of income equity

\section{ACM Reference Format:}

Xing Li and Yiwen Chen. 2021. The Impact of R\&D Employees' Income on Work Engagement in High-tech Industries: Based on A Moderated Mediation Model. In The 2021 12th International Conference on E-business, Management and Economics (ICEME 2021), fuly 17-19, 2021, Beijing, China. ACM, New York, NY, USA, 7 pages. https://doi.org/10.1145/3481127.3481185

\section{INTRODUCTION}

In recent years, the wages of R\&D employees in high-tech industries have risen sharply. According to the industry category data of urban non-private units and urban private units released by the Chinese National Bureau of Statistics for 2019, the average wages of information transmission, software and information technology

Permission to make digital or hard copies of all or part of this work for personal or classroom use is granted without fee provided that copies are not made or distributed for profit or commercial advantage and that copies bear this notice and the full citation on the first page. Copyrights for components of this work owned by others than ACM must be honored. Abstracting with credit is permitted. To copy otherwise, or republish, to post on servers or to redistribute to lists, requires prior specific permission and/or a fee. Request permissions from permissions@acm.org.

ICEME 2021, fuly 17-19, 2021, Beijing, China

(C) 2021 Association for Computing Machinery.

ACM ISBN 978-1-4503-9006-4/21/07 ..\$15.00

https://doi.org/10.1145/3481127.3481185
Yiwen Chen

CAS Key Laboratory of Behavioral Science, Institute of

Psychology. and Department of PsychologyUniversity of

Chinese Academy of Sciences

chenyw@psych.ac.cn

services and scientific research and technology services are among the best [1]. At the same time, the income inversion phenomenon in high-tech industry is very serious. In order to solve the problem of internal employee treatment, many companies immediately improve the salary of internal staff, but lead to a sharp increase in enterprise costs.

Therefore, it has become one of the important issues for HR in high-tech industry to explore the relationship between R\&D employees' income and employees' work attitude and behavior, and to study the influence of the benefits provided by enterprises on employees' work attitude and behavior.

\section{THEORETICAL BASIS AND RESEARCH HYPOTHESIS}

\subsection{Job demand-resource theory}

The job demand-resource model was proposed by Bakker and Demerouti, who pointed out that occupational stress and tension are caused by work demands and alleviated by work resources [2]. Theoretically, the JD-R model assumes two processes. One is the process of energy conversion. It is showed that high-demand work depleted the energy reserves of employees. The other is the motivational process. The lack of effective resources to deal with high-demand work, which leads to mental withdrawal or disengagement [3].

\subsection{Social exchange theory}

In the 1960s, the scholar Homan put forward the social exchange theory [4], which pointed out that all human behaviors are affected by exchange behavior and exchange behavior can bring people expected returns. As the object of social exchange, it contains resources such as money, service, information, and emotion [5].

\subsection{Work engagement}

The concept of work engagement was first put forward by Kahn, who defined it as organization members control themselves so that they can combine themselves with their job roles [6].

Schaufeli et al. conducted a series of studies on work engagement, believing that work engagement is a positive and complete emotional and cognitive state related to work and dividing work engagement into three dimensions: vitality, dedication and concentration [7].

There are two main factors that affect the employee's work engagement in the enterprise. One is the employee's personal resources, the other is the work factor [8]. For example, Schaufeli, Bakker and Vanrhenen found that work characteristics had a predictive effect on employees' work engagement after one year [7]. 
May, Gilson and Harter believed that work reward was positively correlated with psychological security, and the benefits individuals gained in the organization would change their work engagement [8].

\subsection{Income and work engagement}

Based on the job demand-resource model, Schaufeli and Bakker point out that job requirements and lack of job resources are positively correlated with job burnout, while job resources predict work engagement [7].

Bakker, Demerouti and Taris et al. pointed out that wage income, as an important work resource, can enhance the internal and external motivation of employees [9]. A study on the relationship between sales personnel income and organizational commitment and work engagement in the retail industry shows that income is positively correlated with employee work engagement [10].

Based on the work demand-resource model, this paper takes income as one of the work resources and puts forward the following hypothesis.

$\mathrm{H} 1$ : the income of R\&D employees in high-tech industry has a significant positive impact on work engagement.

\subsection{The mediating effect of job satisfaction and organizational commitment}

The systematic study of job satisfaction began in the 1930s [4], which studied the evaluation of various dimen- sions of job satisfaction. Robbins defined job satisfaction as the general attitude of individuals towards their work, and emphasized the compensation employees get from their work [12]. Zhang Shuhan defined job satisfaction from the perspective of individual's attitude towards work environment and work itself [13].

Organizational commitment refers to an attitude or psychological state that describes the relationship between employees and employers, and it is used to describe employees' loyalty to the company and their willingness to serve in the enterprise for a long time. Porter believes that organizational commitment is employees' emotional intention of organizational value [14]. Meyer et al. propose that organizational commitment consists of three components: Emotional commitment, continuous commitment and normative commitment [15].

According to the theory of social exchange, all human social activities can be summed up as one exchange. Individuals receiving preferential treatment may return the exchange obligation [16]. Employees receive income from the enterprise in exchange for giving back their attitudes and behaviors corresponding to the organization and work. Wang Le found that there is a significant and stable positive correlation between relative income and job satisfaction [17]. The research of Shan Zhixia shows that absolute income has a positive effect on job satisfaction [18].

Allen and Shanock have shown that wage income significantly affects an individual's organizational commitment [19]. Employees with high salaries can feel the organization's affirmation and recognition of their work, which will promote them to increase their recognition and attachment to the organization and enhance their emotional commitment to the organization [11]. Therefore, this paper proposes the following hypothesis:
H2: income has a significant positive impact on job satisfaction and organizational commitment.

At the organizational level, employees' job satisfaction and organizational commitment can also be considered as a kind of work resource. According to the job demand-resource model, the more work resources there are, the more positively they can predict employees' work engagement.

The studies of Yao Haijuan et Al. have found that employee job satisfaction has a significant positive predictive effect on work engagement [20]. Compared with organizational fairness and sense of organizational support, organizational commitment has a direct impact on work engagement [21]. Therefore, this paper proposes the following hypothesis:

H3: job satisfaction and organizational commitment have a significant positive impact on work engagement.

$\mathrm{H} 4$ : job satisfaction and organizational commitment play a mediating role between employee income and work engagement.

\subsection{The moderating effect of sense of income equity}

Fairness is the degree to which the members of a society can accept the way or result of distribution of valuable resources according to a certain social consensus of justice principle [22]. The sense of income equity is a subjective feeling of employees about their own organization's salary system and personal remuneration [23].

Berkowitz et al. Pointed out that employees' income from the organization has two functions. One is to directly meet the basic material needs, and the other is to meet the needs of self and self-esteem through relative value [24]. As an important aspect of organizational justice, sense of income equity directly affects employees' work performance, work enthusiasm and work engagement [25]. Employees are more sensitive to income distribution, and internal equity has a significant impact on employee job satisfaction [26]. Therefore, this paper puts forward the following hypothesis.

H5: the sense of income equity has a significant moderating effect on the relationship between employees' income level and work engagement.

H6a: the sense of income equity significantly moderated the mediating effect of job satisfaction on income level and work engagement.

H6b: the sense of income equity significantly moderated the mediating effect of organizational commitment between income level and job engagement.

Based on the research hypothesis $\mathrm{H} 1$ to $\mathrm{H} 6$, this paper constructs a moderated mediation model, as shown in Figure 1.

\section{METHODOLOGY}

\subsection{Research sample}

Through online questionnaires, the industry was restricted to hightech industries. A total of 300 questionnaires were distributed and 300 questionnaires were actually recovered. After eliminating the questionnaires with non-R\&D positions, too short or too long answering time and failing to pass the polygraph test, 159 questionnaires were valid, with an effective rate of $53 \%$. Among the 159 valid samples, males accounted for $63.5 \%$ and females $36.5 \%$, and $97.5 \%$ 


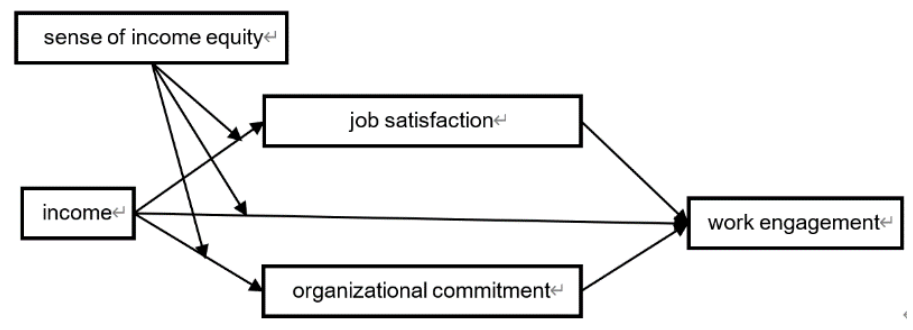

Figure 1: Theoretical model

of the employees have a bachelor's degree or above, which is in line with the high-tech industry's requirement for R\&D personnel with a higher education background. $52.8 \%$ of the employees are between 26 and 30 years old. $57.2 \%$ of employees are married.74.2\% of employees have worked in the same company for more than three years.

\subsection{Variable measurement}

3.2.1 Income. It is the total income received by an individual from the company during the previous year, including salary, bonuses, subsidies, options, etc. Consider that employees may be reluctant to reveal the exact value of their income, so let them choose the range of their personal annual income.

Among them, those below 100,000 are recorded as 1, and those between 110,000 and 130,000 are recorded as 2, and those between 140,000 and 160, 000 are recorded as 3 , and those between 170,000 and 200, 000 are recorded as 4, and those between 200,000 and 400, 000 are recorded as 5 to 9 respectively, and those between 400,000 and 700,000 are recorded once every 50,000 as 10 to 14 respectively, and those above 700,000 is recorded as 15 .

3.2.2 Work engagement. It was adopted that a simplified version of the work engagement scale developed by Schaufeli et al. [27], Likert 7 scale. There were nine questions. The example of the question was that I feel my energy burst out in work. The Cronbach's $\alpha$ coefficient of the scale in this study is 0.95 .

3.2.3 Job satisfaction. The job happiness dimension of the employee happiness measurement scale proposed by Zheng, Zhu, Zhao and Zhang [28] was used to measure job satisfaction. There are 6 questions in the Likert 7-level scale. The example of the question was that I am very satisfied with the work I am doing. The Cronbach's $\alpha$ coefficient of the scale in this study is 0.90 .

3.2.4 Organizational commitment. It was adopted that the local organizational commitment scale developed by domestic scholar Liu Xiaoping [29]. The scale consists of 16 questions, Likert 5level scale. The example of the question was that I am willing to make extra efforts to help the business succeed in business. The Cronbach's $\alpha$ coefficient of the scale is 0.93 .

3.2.5 Sense of income equity. Combined with the actual situation of this study, the scale of Deng Jinying [30] and Ma Shujie [25] was adapted, and finally 10 topics, Likert 5-level scale, were formed. The example of the question was that my salary was fair in terms of my workload and responsibilities. The Cronbach's $\alpha$ coefficient of the scale is 0.92 .

3.2.6 Control variables. According to the results of previous studies, gender, academic background, age of division and marriage were used as control variables in this research.

\section{RESEARCH RESULT}

\subsection{Data analysis}

4.1.1 Common method deviation test. SPSS 24.0 software was used for exploratory factor analysis of each variable. After unrotated factor analysis, the maximum factor accounted for $40.65 \%$ of the total variation, which was lower than the judgment standard of $50 \%$, indicating that there was no serious common method deviation problem in the measurement [31] [32].

4.1.2 Confirmatory factor analysis. Amos 24.0 was used to conduct confirmatory factor analysis for each scale, and the results of each indicator of each scale are shown in Table 1. The results show that all scales have good structural validity.

4.1.3 The correlation statistical analysis of each research sample. The correlation coefficients of each research variable are shown in Table 2. As can be seen from Table 2, employee income is significantly positively correlated with work engagement $(r=0.19, \mathrm{p}<0.05)$, job satisfaction $(\mathrm{r}=0.18, \mathrm{p}<0.05)$, and organizational commitment $(\mathrm{r}=0.23, \mathrm{p}<0.01)$. Job satisfaction is significantly positively correlated with work engagement $(\mathrm{r}=0.78, \mathrm{p}<0.01)$, and organizational commitment is also significantly positively correlated with work engagement $(\mathrm{r}=0.72, \mathrm{P}<0.01)$. The results of correlation analysis provide preliminary support for hypothesis testing.

\subsection{Hypothesis testing}

4.2.1 The impact of income on work engagement. Firstly, the simple and direct effect of income on work engagement is examined by using the analytic hierarchy process. The data showed that income had a significant positive effect on work engagement after controlling for demographic variables $(B=0.03, \mathrm{p}<0.05)$. So, $\mathrm{H} 1$ was verified.

4.2.2 Mediate effect analysis. In this paper, Process for SPSS (version 22.00) was adopted as the mediating effect testing tool [28] [36]. Model 4 was selected. The non-parametric percale Bootstrap method based on deviation correction was repeated for 5000 times. Table 3 shows the results (B is no standardized coefficients). 
Table 1: Validation Factor Analysis Results

\begin{tabular}{llllllll}
\hline Degree of fit & Chi-square value & Degree of freedom & Chi-square/DOF & NFI & IFI & CFI & RMSEA \\
\hline work engagement & 39.02 & 21.00 & 1.86 & 0.96 & 0.98 & 0.98 & 0.07 \\
Job satisfaction & 10.75 & 8.00 & 1.34 & 0.98 & 1.00 & 1.00 & 0.05 \\
Organizational & 145.69 & 117.00 & 1.25 & 0.91 & 0.98 & 0.98 & 0.04 \\
commitment & & & & & & \\
Sense of income equity & 55.21 & 32.00 & 1.73 & 0.95 & 0.98 & 0.98 & 0.07 \\
\hline
\end{tabular}

Table 2: Statistical Analysis of Correlation of Study Samples

\begin{tabular}{|c|c|c|c|c|c|c|c|c|c|c|c|}
\hline Variable & 1 & 2 & 3 & 4 & 5 & 6 & 7 & 8 & 9 & 10 & 11 \\
\hline 1. gender & 1 & & & & & & & & & & \\
\hline 2. age & -0.01 & 1 & & & & & & & & & \\
\hline 3. education & -0.1 & 0.07 & 1 & & & & & & & & \\
\hline 4. years & -0.04 & $.79^{* *}$ & $-.17^{*}$ & 1 & & & & & & & \\
\hline 5. years & 0.12 & $.24^{* *}$ & -0.04 & $.32^{* *}$ & 1 & & & & & & \\
\hline 6. marital status & 0.06 & $.17^{*}$ & 0.02 & 0.15 & $.18^{*}$ & 1 & & & & & \\
\hline 7. income & 0.08 & $.16^{*}$ & $.20^{*}$ & $.20^{*}$ & $.21^{* *}$ & 0.03 & 1 & & & & \\
\hline 8. job satisfaction & -0.03 & 0.07 & -0.03 & 0.06 & 0.1 & -0.03 & $.18^{*}$ & 1 & & & \\
\hline 9. organization commitments & 0.01 & 0.06 & -0.13 & 0.13 & $.20^{*}$ & -0.05 & $.23^{* *}$ & $.69^{* *}$ & 1 & & \\
\hline 10. Sense of income equity & -0.06 & -0.12 & -0.1 & -0.08 & 0.14 & -0.02 & $.21^{* *}$ & $.55^{* *}$ & $.69^{* *}$ & 1 & \\
\hline 11. Work engagement & -0.04 & 0.07 & 0.14 & 0.01 & 0.02 & 0.02 & $.19^{*}$ & $.73^{* *}$ & $.72^{* *}$ & $.55^{* *}$ & 1 \\
\hline
\end{tabular}

Note: $\mathrm{N}=159,{ }^{*}$ indicates significant at $\mathrm{p}<0.05$ level, ${ }^{* *}$ indicates significant at $\mathrm{p}<0.01$ level.

Table 3: Results of Regression Analysis of Mediating Effects

\begin{tabular}{|c|c|c|c|c|c|c|c|c|c|c|c|c|c|c|c|}
\hline \multirow[t]{2}{*}{ Variable } & \multicolumn{5}{|c|}{ work engagement } & \multicolumn{5}{|c|}{ Job satisfaction (M1) } & \multicolumn{5}{|c|}{ Organizational commitment (M2) } \\
\hline & $\mathrm{B}$ & SE & $\mathrm{t}$ & LLCI & ULCI & $\mathrm{B}$ & SE & $\mathrm{t}$ & LLCI & ULCI & $\mathrm{B}$ & SE & $\mathrm{t}$ & LLCI & ULCI \\
\hline constant & -1.82 & 0.39 & -4.67 & -2.6 & -1.1 & 5.62 & 0.39 & 14.46 & 4.85 & 6.39 & 3.90 & 0.25 & 15.57 & 3.40 & 4.39 \\
\hline Income & $\begin{array}{l}- \\
0.004\end{array}$ & 0.01 & -0.26 & -0.03 & 0.02 & 0.05 & 0.02 & $2.23^{*}$ & 0.01 & 0.09 & 0.04 & 0.01 & $2.94^{* *}$ & 0.01 & 0.07 \\
\hline JS & 0.44 & 0.07 & $6.67^{* *}$ & 0.31 & 0.57 & & & & & & & & & & \\
\hline OC & 0.75 & 0.1 & $7.34^{* *}$ & 0.55 & 0.95 & & & & & & & & & & \\
\hline $\mathrm{R} 2$ & 0.68 & & & & & 0.05 & & & & & 0.11 & & & & \\
\hline $\mathrm{F}$ & $46.03^{* *}$ & & & & & 1.45 & & & & & $3.91^{* *}$ & & & & \\
\hline
\end{tabular}

Note :(1) $\mathrm{N}=159,{ }^{*}$ Indicates significant at $\mathrm{p}<0.05$ level, ${ }^{* *}$ Indicates significant at $\mathrm{p}<0.01$ level; (2) The $\mathrm{B}$ values in the table are non-standardized regression coefficients; (3) 95 per cent of the Bootstrap value used to estimate the deviation correction confidence interval, the number of repeated samples is 5000 ; (4) JS=job satisfaction, $\mathrm{OC}=$ organizational commitment.

The results showed that income had a significant positive effect on job satisfaction ( $\mathrm{M} 1, \mathrm{~B}=0.05, \mathrm{p}<0.05)$, income had a significant positive effect on organizational commitment $(\mathrm{M} 2, \mathrm{~B}=0.04, \mathrm{p}<0.01)$. So, $\mathrm{H} 2$ was verified.

Meanwhile, job satisfaction had a significant positive effect on work engagement $(B=0.44, p<0.01)$, and organizational commitment had a significant positive effect on work engagement $(B=0.75$, $\mathrm{p}<0.01$ ), respectively. So, H3 was verified.

Furthermore, the mediating effect of job satisfaction and organizational commitment was tested by using the deviation correction non-parametric percentile Bootstrap method. The results showed that the indirect effect value of job satisfaction was $0.02(\mathrm{p}<0.01)$, and the Boot $95 \%$ confidence interval was $(0.004,0.04)$. It also showed that the indirect effect value of organizational commitment was $0.03(\mathrm{p}<0.01)$, the confidence interval was $(0.01,0.05)$, and the confidence interval was not 0 . This suggests that in the staff work into the path of the income effect, job satisfaction and organizational commitment of the intermediary effect significantly. So, H4 was verified.

4.2.3 Moderated mediating effect analysis. Current mainstream methods for verifying moderated mediating effect include Bootstrap-based subgroup analysis, coefficient product method and difference analysis method. The coefficient product method has 
The Impact of R\&D Employees' Income on Work Engagement in High-tech Industries: Based on A Moderated Mediation Model ICEME 2021, July 17-19, 2021, Beijing, China

Table 4: Statistical Analysis of Correlation of Study Samples

\begin{tabular}{|c|c|c|c|c|c|c|c|c|c|c|c|c|c|c|c|}
\hline \multirow[t]{2}{*}{ Variable } & \multicolumn{5}{|c|}{ Job satisfaction (M1) } & \multicolumn{5}{|c|}{ Organizational commitment(M2) } & \multicolumn{5}{|c|}{ work engagement } \\
\hline & $\mathrm{B}$ & SE & $\mathrm{t}$ & LLCI & ULCI & $\mathrm{B}$ & $\mathrm{SE}$ & $\mathrm{t}$ & LLCI & ULCI & $\mathrm{B}$ & SE & $\mathrm{t}$ & LLCI & ULCI \\
\hline Income & 0.00 & 0.02 & -0.10 & -0.04 & 0.04 & 0.01 & 0.01 & 0.54 & -0.02 & 0.03 & -0.01 & 0.01 & -0.33 & -0.03 & 0.02 \\
\hline JS & & & & & & & & & & & 0.40 & 0.08 & $5.29^{* *}$ & 0.25 & 0.55 \\
\hline $\mathrm{OC}$ & & & & & & & & & & & 0.75 & 0.12 & $6.27^{* *}$ & 0.52 & 0.98 \\
\hline SIE & 0.80 & 0.09 & $8.47^{* *}$ & 0.61 & 0.98 & 0.62 & 0.05 & $11.48^{* *}$ & 0.52 & 0.72 & 0.11 & 0.10 & 1.09 & -0.09 & 0.31 \\
\hline Income ${ }^{*} \mathrm{SIE}$ & 0.07 & 0.03 & $2.35^{* *}$ & 0.01 & 0.13 & 0.03 & 0.02 & $1.99^{*}$ & 0.00 & 0.06 & -0.15 & 0.02 & -0.81 & -0.06 & 0.03 \\
\hline R2 & 0.59 & & & & & 0.73 & & & & & 0.83 & & & & \\
\hline $\mathrm{F}$ & 11.67 & & & & & 24.03 & & & & & $30.05^{* *}$ & & & & \\
\hline
\end{tabular}

Note :(1) $\mathrm{N}=159,+$ mean significant at $\mathrm{p}<0.1,{ }^{*}$ Indicates significant at $\mathrm{p}<0.05$ level, ${ }^{* *}$ Indicates significant at $\mathrm{p}<0.01$ level; (2) The B values in the table are non-standardized regression coefficients; (3) 95 percent of the Bootstrap value used to estimate the deviation correction confidence interval, the number of duplicate samples was 5000; (4) SIE = sense of income equity, JS = job satisfaction.

more advantages than the other two methods in verifying the firststage adjustment or the second-stage adjustment [33]. In this paper, process for SPSS (version 24.00) was used as an adjusted mediating effect testing tool. Model 8 was used, Bootstrap program was adopted, and repeated sampling was performed 5000 times. Table 4 shows the operation results (B is non-standardized coefficient).

The results showed that the interaction term of income and sense of income equity had no significant regression on the dependent variable of work engagement $(B=-0.15, p>0.1)$, which indicated that sense of income equity could not regulate the relationship between income and work engagement. At the same time, the interaction terms of income and sense of income equity have significant regression coefficients on the mediating variables of job satisfaction $(\mathrm{B}=0.07, \mathrm{P}<0.01)$ and organizational commitment $(\mathrm{B}=0.03, \mathrm{P}<0.01)$, indicating that sense of income equity moderates the relationship between income, job satisfaction and organizational commitment, and moderates the mediating effect.

In conclusion, sense of income equity has no significant moderating effect on the relationship between income and work engagement, and $\mathrm{H} 5$ is not verified. However, perceived income equity significantly moderates job satisfaction and the mediating effect of organizational commitment on the relationship between income and work engagement. H6a and H6b are established. As can be seen from the above, the moderated mediation model is supported by the research data.

In order to more intuitively present the mediating role of organizational commitments under different sense of income equity levels, a simple slope diagram is drawn, as shown in Figure 2 and Figure 3. OC means organiza-tional commitment, and SIE means sense of income equity. A simple slope analysis was used to further examine the moderation effect of sense of income equity on organizational commitment and work engagement. In this study, one standard deviation was used as the standard deviation of the average sense of income equity. People with a high sense of income equity $(\mathrm{M}+1 \mathrm{SD})$ and those with a low sense of income equity (M-1SD) were selected to conduct a simple slope test. The results showed that the organizational commitment level of high and low sense of income equity could significantly predict work engagement. In the case of high sense of income equity, $\mathrm{B}=0.94, \mathrm{t}=5.48,95 \%$ confidence interval $[0.6,1.27], \mathrm{p}<.01$. And in the case of low sense of income equity,

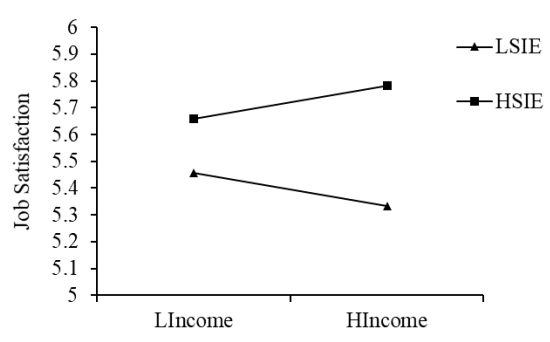

Figure 2: The moderating effect of sense of income equity on Income and job satisfaction

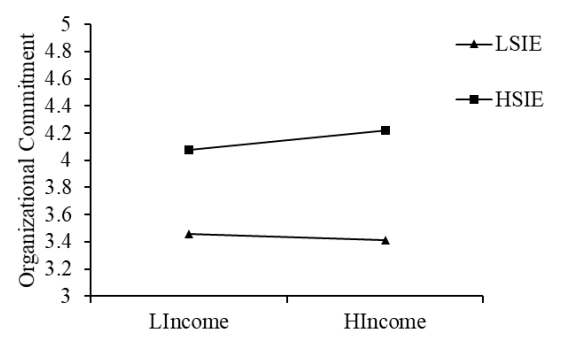

Figure 3: The moderating effect of sense of income equity on Income and organizational commitment

$\mathrm{B}=0.58, \mathrm{t}=4.12,95 \%$ confidence interval $[0.3,0.85], \mathrm{p}<.01$. This indicates that organizational commitment has a stronger positive effect on work engagement when higher sense of income equity is perceived. 


\section{RESEARCH CONCLUSION AND DISCUSSION}

\subsection{Conclusions}

This study conducted an empirical study on the relationships among income, the sense of income equity, job satisfaction, organizational commitment, and work engagement. The results show that income is positively correlated with job satisfaction, organizational commitment and work engagement. At the same time, both job satisfaction and organizational commitment have significant mediating effects on the effect of income on work engagement. In addition, the sense of income equity has a significant moderating effect on the effect of income on work engagement through two mediating variables. In the case of the high sense of income equity, income positively affects job satisfaction and organizational commitment, while in the case of low sense of income equity, income negatively affects job satisfaction and organizational commitment. The higher the perceived income equity, the stronger the mediating effect of job satisfaction and organizational commitment.

Job satisfaction and organizational commitment of employees are important psychological feelings of employees, which can significantly positively predict work engagement [19] [34] [35]. The results of previous studies are consistent with the results of $\mathrm{H} 3$ in this study. The sense of income equity has a significantly positive impact on job satisfaction, organizational commitment and job engagement, again proving the results of previous studies [33] [26].

As a result, this study theoretically further verified the social exchange theory, and the content of the theory of social comparison, and also extends the theory of empirical research to the above. At the same time, the results of the study on organization more comprehensive and objective understanding of income provides a meaningful point of view, the choices of the strategies of enterprise wage have certain guiding significance, which is the organization, we should not only pay attention to the absolute income of employees, but also pay attention to how employees feel about the income. The sense of income equity is even more important than the income itself. For example, employees' judgment on the income level is unfair, and enterprises need to sort out the salary structure and reasonably distribute the salary.

\subsection{Management implications}

Optimize the income structure and strengthen the income traction of the core staff. The organization should pay attention to the positive role of employee's income on their work attitude and behavior. The organization should design the income structure of employees according to the different conditions of employees to increase the attraction of the organization to employees for high-tech R\&D employees, especially for core backbone and experts.

The organization should do a good job of internal and external staff income inventory, and design a reasonable salary adjustment policy. For example, check the market salary level of the industry regularly, and strive to ensure that the salary level of the core backbone personnel is above 75th percentile of the market salary. At the same time, pay attention to the income gap of the new and old employees, especially reduce the upside down reasonably.
Actively track employees' mentality, guide and help them improve their psychological resources. By organizing employee activities regularly, encouraging supervisor support and advocating senior management care, the organization can promote the improvement of employees' work engagement by enhancing psychological resources such as employee job satisfaction and organizational commitment.

\subsection{Research Limitations and Prospects}

Although the research on the relationship between income and work engagement has certain theoretical and practical significance, there are still some limitations in the research design, research samples and so on. First of all, the questionnaire data of this study is cross-sectional data, and the future research can use longitudinal data to verify the theoretical research model more effectively. Secondly, this study mainly takes the R\&D personnel of high-tech industry as the sample, and the scope of the sample can be expanded in the future. Third, this study only verified the effect of income on work engagement through job satisfaction and organizational commitment. Future research can continue to explore the role of other psychological resources. Finally, this paper verifies the moderating effect of income justice sense, and future research can further explore whether there are other regulatory variables.

\section{ACKNOWLEDGMENTS}

We gratefully acknowledged staff of those who helped to acquire the questionnaires and written informed consent. The corresponding author is Yiwen Chen, and his email is chenyw@psych.ac.cn.

\section{REFERENCES}

[1] The average annual wage of urban non-private sector employees is 90501 yuan in 2019. (2020, May 15), from: http://www.stats. gov. cn/ tjsj/zxfb/202005/ t20200515_1745764.Html

[2] Xanthopoulou, D., Bakker, A. B., Demerouti, E., \& Schaufeli, W. B. (2007). The role of personal resources in the job demands-resources model. International journal of stress management, 14(2), 121.

[3] Schaufeli, W. B., \& Bakker, A. B. (2004). Job demands, job resources, and their relationship with burnout and engagement: A multi-sample study. Journal of Organizational Behavior: The International Journal of Industrial, Occupational and Organizational Psychology and Behavior, 25(3), 293-315

[4] Schminke, M., Cropanzano, R., \& Rupp, D. E. (2002). Organization structure and fairness perceptions: The moderating effects of organizational level. Organizational Behavior and Human Decision Processes, 89(1), 881-905

[5] Eisenberger, R., \& Rhoades, L. (2001). Incremental effects of reward on creativity. Journal of personality and social psychology, 81(4), 728.

[6] Kahn, W. A. (1990). Psychological conditions of personal engagement and disengagement at work. Academy of management journal, 33(4), 692-724. Schaufeli, Wilmar B.1( W.Schaufeli@fss.uu.unl);Bakker, Arnold B.1.Job demands, job resources, and their relationship with burnout and engagement: a multi-sample study[J].Journal of Organizational Behavior.2004,Vol.25(No.3):293-315.

[7] Schaufeli WB, Bakker AB, Van Rhenen W.(2009).How changes in job demands and resources predict burnout, work engagement, and sickness absenteeism[J].Journal of Organizational Behavior, 30 (7) :893 917.

[8] May, D. R., Gilson, R. L., \& Harter, L. M. (2004). The psychological conditions of meaningfulness, safety and availability and the engagement of the human spirit at work. Journal of occupational and organizational psychology, 77(1), 11-37.

[9] Bakker, A. B., Demerouti, E., Taris, T. W., Schaufeli, W. B., \& Schreurs, P. J. (2003). A multigroup analysis of the job demands-resources model in four home care organizations. International Journal of stress management, 10(1), 16.

[10] Zhou Wenxia, Pan Jingzhou. (2011).The effect of sales staff's income level on job engagement in retail firms: A moderated mediating effect model [J]. Journal of Beijing Technology and Business University (Social Science Edition). (4):7-14.

[11] Saridakis, G.;Lai, Y.Muoz Torres, R.I.;Gourlay, S.(2018). Exploring the relationship between job satisfaction and organizational commitment: an instrumental variable approach[J].International Journal of Human Resource Management.1-31. 
[12] Spence, Janet T. U Texas, Austin, US; Robbins, Ann S. (1992).Workaholism: Definition, measurement, and preliminary results.[J].Journal of Personality Assessment. 58(1):160-178

[13] Zhang Shuhan.( 2004). A study on personality traits, job satisfaction and resignation intention of university contractors [D]. National Sun Yat-sen University, Taiwan.

[14] Porter, L. W., Steers, R. M., Mowday, R. T., \& Boulian, P. V. (1974). Organizational commitment, job satisfaction, and turnover among psychiatric technicians. Journal of applied psychology, 59(5), 603-609.

[15] Meyer, John P.. U; Allen. (1993).Commitment to organizations and occupations Extension and test of a three-component conceptualization. [J].Journal of Applied Psychology. 78(4):538-551.

[16] Russell Cropanzano;Deborah E. Rupp;Carolyn J. Mohler;Marshall Schminke.(2001).Three roads to organizational justice[J]. 1-113.

[17] Wang Le. (2015).A study on the impact of large income on job satisfaction: An empirical analysis based on micro data of China General Social Survey [D]. Southwest University of Political Science and Law, Chongqing.

[18] Shan Zhixia. (2017).An economic study on the relationship between absolute income, relative income and job satisfaction [J]. Productivity research.(10):19-25.

[19] Allen, D. G., \& Shanock, L. R. (2013). Perceived organizational support and embeddedness as key mechanisms connecting socialization tactics to commitment and turnover among new employees. Journal of Organizational Behavior, 34(3), 350-369.

[20] Yao Haijuan, Zhang Bin, Li Lei.(2013). An empirical analysis of the relationship between employee organizational commitment, job satisfaction and job engagement [J]. Journal of Chifeng University (Natural Science Edition). (14):142-144.

[21] Li Jinbo.(2007). A study on organizational factors affecting employee job involvement [J]. psychology. (1).

[22] Soltan,E,K.(1982).Equality, Justice and Rectification: An Exploration in Normative Sociology.Contemporary Sociology,11(4),441-442.

[23] Han Rui, Li Jingping. (2013).The Influence of Perceived Pay Equity and Satisfaction on Behavioral Performance of Civil Servants [J]. Economic restructuring. (3):3437.

[24] Berkowitz, L., Fraser, C., Treasure, F. P., \& Cochran, S. (1987). Pay, equity, job gratifications, and comparisons in pay satisfaction. Journal of Applied Psychology,
$72(4), 544$.

[25] Ma Shujie. (2018).The Relationship between Pay Equity, Employee Engagement and Job Performance: The Moderating Role of Employee Emotional Intelligence [D]. Shandong University, Shandong.

[26] Jiang Yinglai,Jiang jinxiang. (2012).The Impact of Income Distribution on Employee Job Satisfaction in Colleges and Universities: Based on the Survey of Z College [J]. Journal of Shanghai Business College.(6):56-59.

[27] Schaufeli, W. B., Salanova, M., González-Romá, V., \& Bakker, A. B. (2002). The measurement of engagement and burnout: A two sample confirmatory factor analytic approach. Journal of Happiness studies, 3(1), 71-92.

[28] Zheng, Xiaoming1; Zhu, Weichun2; Zhao, Haixia1; Zhang, Chi1.(2015).Employee well-being in organizations: Theoretical model, scale development, and crosscultural validation. [J].Journal of Organizational Behavior. 36(5):621-644

[29] Liu Xiaoping. (2012).Employee Organizational Commitment in Chinese Context [M]. Social Sciences Academic Press, Beijing.171-172.

[30] Deng Jinying. (2015).The influence of salary equity perception and career management perception on turnover intention of IT technicians: An empirical study using occupational commitment as a mediating variable [D]. South China University of Technology, Guangdong.

[31] Podsakoff, Philip M.;MacKenzie, Scott B.;Jeong-Yeon Lee;Podsakoff, Nathan P.(2003).Common Method Biases in Behavioral Research: A Critical Review of the Literature and Recommended Remedies[J].Journal of Applied Psychology.88(5):879.

[32] Kim, T. Y., \& Leung, K. (2007). Forming and reacting to overall fairness: A crosscultural comparison. Organizational Behavior and Human Decision Processes, 104(1), 83-95.

[33] Fang Jie, Zhang Minqiang,(2014). Gu Honglei, Moderated Mediation Model Test Based on Asymmetric Interval Estimation[J]. Advances in Psychological Science, (10) : 1660-1668

[34] Wang Dan. (2017). The Influence of Preschool Teachers' Job Satisfaction on Job Engagement. Journal of Ning Bo institute of education (04), 42-46.

[35] Bose, I., \& Maheshwary, R. (2019). Reward Program, Job Satisfaction \& Employee Engage.

[36] Hayes AF. Introduction to Mediation Moderation, and Conditional Process Analysis: A Regression- based Approach[M]. New York: Guilford Press, 2013. 